\title{
NURETTA DEVIANA: CHILDREN BEHAVIORAL SHAPING MELALUI PEMBELAJARAN BAHASA INGGRIS BERBASIS AKULTURASI BUDAYA BAGI SISWA SEKOLAH DASAR
}

\author{
Eko Heriyanto, Adhitya Wisnumurti, Adityo Putro Wicaksana \\ Universitas AKI \\ eko.heriyanto@unaki.ac.id
}

\begin{abstract}
English has become part of the education curriculum that must be taught to students. Therefore, many schools strive to provide the best English teaching and learning systems and methods for their students. One of them is Nuretta Deviana which is an alternative model of learning English. The purpose of this research is to explain the steps of implementing Nuretta Deviana, find and explain the skills and language components that can be learned through Nuretta Deviana, explain the children behavioral forming through NUretta Deviana, find and overcome the obstacles that arise in the implementation of Nuretta Deviana. The approach used is descriptive qualitative based on literature review. Primary data were collected using documentation techniques during the Nuretta Deviana process, performances, and interviews with stakeholders and educators (English teachers in schools). Secondary data were collected using the literature review method. The results of this study stated that Nuretta Deviana can be done by holding preparations, performances and assessments. Nuretta Deviana can hone student' English skills and components. Diligent, hard work, discipline and tolerance characteristic are implicitly formed through the script which acculturate local culture and British culture. Barriers internally and externally can be overcome with solutions that are carried out continuously.
\end{abstract}

Keywords: nursery rhymes, reader response theory

\section{PENDAHULUAN}

Indonesia merupakan salah satu negara yang menyadari peranan strategis bahasa tak terkecuali bahasa Inggris. Indonesia telah berusaha dengan berbagai cara untuk meningkatkan kualitas pendidikan bahasa Inggris di seluruh pelosok negeri. Bahasa Inggris telah menjadi bagian dari kurikulum pendidikan yang harus diajarkan kepada peserta didik. Oleh karena itu, banyak sekolah berupaya untuk menyediakaan sistem dan metode belajar mengajar bahasa Inggris yang terbaik bagi siswa mereka. Hal ini bertujuan untuk mencapai target yang telah mereka rencanakan, terutama pada ujian nasional, dan pihak sekolah juga berharap setelah lulus sekolah anak didik mereka memiliki kompetensi 
bahasa Inggris yang memadai baik lisan maupun tertulis.

Ketika mempelajari bahasa Inggris, keterampilan bahasa Inggris itu sendiri harus dikuasai baik listening, speaking, reading, maupun writing. Kemudian, siswa juga harus memperhatikan komponen bahasa Inggris seperti vocabulary (perbendaharaan kata), grammatical structures (tata bahasa), pronunciation (pelafalan). Selain kedua hal tersebut, para siswa perlu mempelajari budaya bahasa Inggris. Seringkali pembelajaran bahasa melalaikan bagian ini. Padahal setiap bahasa memiliki ciri khas dan budayanya sendiri yang harus dipahami dengan baik. Mempelajari budaya bahasa Inggris menjadi suatu hal yang penting karena akan menerangkan kepada siswa bagaimana bahasa Inggris diterapkan dalam kehidupan nyata sesuai konteksnya.

Namun, ketersediaan fasilitas di sekolah adalah salah satu faktor yang sangat mempengaruhi proses dan hasil pembelajaran. Sekolah di daerah perkotaan telah dilengkapi dengan fasilitas pendukung yang memadai seperti buku, jurnal, majalah, internet dan laboratorium bahasa dengan peralatan belajar mengajar yang lengkap di dalamnya. Hal ini berbeda sekali dengan sekolah yang ada di daerah pedesaan. Siswa hanya berkutat pada text book oriented, sehingga kemampuan mereka dalam berbahasa sangat minim sekali.

Disamping fasilitas, dengan metode dan media yang sesuai serta contohcontoh yang cukup aplikatif, maka akan terbangun suasana kelas yang menyenangkan. Mereka akan mengikuti alur pembelajaran dengan baik dan mengambil manfaat dari proses belajar mengajar tersebut. Namun dalam kenyataannya, masih banyak sekolah yang menerapkan sistem pembelajaran bahasa Inggris yang tidak sesuai dengan kondisi anak didik. Proses pembelajaran bahasa bagi anak seharusnya menarik dan menyenangkan, sehingga mereka bersedia melakukan berbagai aktivitas dalam proses ini dengan senang hati. Hasilnya, para peserta didik dalam mempelajari bahasa tidak hanya mendapatkan suatu bentuk, tetapi juga makna, dan diharapkan bahasa tersebut dapat diaplikasikan dalam kehidupan mereka sehari- hari.

Dari uraian kondisi di atas, peneliti meneliti dan mengembangkan model pembelajaran alternatif pembelajaran bahasa Inggris yaitu NURETTA DEVIANA (Nursery Rhymes Operetta: Developmental and Psychological 
Analysis): suatu bentuk integrasi dunia sastra (lagu anak-anak berbahasa Inggris) pada pendidikan bahasa dengan akulturasi budaya untuk membentuk karakter siswa sekolah dasar. Hal ini berdasarkan asumsi bahwa pengajaran bahasa Inggris harus memperhatikan umur dan karakteristik peserta didik. Nuretta Deviana menampilkan contoh nyata tentang bagaimana bahasa Inggris digunakan dalam bentuk lisan yang sudah didesain dengan menggunakan Developmental Psychological Analysis (DEVIANA). Model pembelajaran tersebut dapat dilakukan kapanpun, dimanapun, dan oleh siapapun yang akan menciptakan suasana pembelajaran semakin hidup dan menyenangkan.

Berdasarkan paparan tersebut, maka rumusan masalah dalam penelitian ini adalah 1). Bagaimana langkah-langkah penerapan Nuretta Deviana ?, 2). Keterampilan dan komponen bahasa Inggris apa sajakah yang dapat dipelajari melalui Nuretta Deviana?, 3). Bagaimana proses pembentukan karakter siswa melalui Nuretta Deviana yang berbasis akulturasi budaya?, 4). Hambatan-hambatan apakah yang akan muncul selama proses pembelajaran?

Adapun tujuan dari penelitian ini adalah menjelaskan secara rinci langkah- langkah penerapan Nuretta Deviana, menerangkan keterampilan apa saja yang dapat dipelajari melalui penerapan Nuretta Deviana dalam pemebelajaran bahasa Inggris, menemukan dan menjelaskan proses pembentukan karakter siswa melalui akulturasi budaya, dan mengetahui hambatan-hambatan yang muncul dan solusinya dalam proses behavioral shaping bagi siswa Sekolah Dasar. Sedangkan manfaat dari penelitian ini adalah selain menjadi acuan untuk kajian lanjutan, Nuretta dapat membantu pembentukan dan pengembangan karakter siswa melalui implementasi model alternatif pembelajaran bahasa Inggris yang sesuai dengan karakteristik anak, sehingga siswa dapat belajar bahasa Inggris dengan rasa senang serta mempelajari pesan moral dari nursery rhymes.

\section{METODE PENELITIAN}

Metode yang digunakan dalam penelitian ini adalah deskriptif kualitatif berdasarkan kajian kepustakaan. Pemilihan metode ini diharapkan dapat memberikan gambaran secara cermat mengenai keadaan atau gejala tertentu pada objek kajian. Dalam hal ini, peneliti berusaha membuat gambaran mengenai langkah- 
langkah dalam melaksanakan Nuretta Deviana dan seluk beluk yang berkaitan dengan pembentukan karakter anak.

Ada dua jenis data yang dgunakan dalam penelitian ini, yaitu data primer dan data sekunder. Data primer dikumpulkan dengan teknik dokumentasi dan observasi lapangan selama proses implementasi Nuretta Deviana. Data sekunder dikumpulkan dengan metode telaah dan analisis kepustakaan sebagai sumber referensi dengan analisis kritis meliputi bukubuku/ informasi tentang karakteristik anak, teori reader- response dan hal yang menunjang topik pembahasan. Sumber kajian ini diharapkan dapat memperkuat dan mempertajam hasil penelitian.

Adapun sebagai data lapangan implementasi dan deskripsi implementasi Nuretta, peneliti mengambil data tersebut di SD Labschool Universitas Negeri Semarang yang notabenenya menerapkan lima hari sekolah, kebutuhan metode pembelajaran yang variatif dalam berbagai mata pelajaran, dan ketersediaan waktu yang mencukupi dalam pembelajaran.

\section{HASIL PENELITIAN}

\subsection{Langkah-Langkah Implementasi Nuretta Deviana}

Untuk memudahkan cara mengelola penerapan Nuretta Deviana, maka perlu dibagi dalam tiga tahapan yaitu tahap persiapan, tahap pelaksanaan, dan tahap penilaian. Dalam tahap persiapan, yang dilakukan adalah pembuatan naskah Nuretta dan latihan (rehearsal). Pembuatan naskah Nuretta dilakukan dengan cara sebagai berikut:

a.Menentukan tema

Tema yang sesuai dengan anakanak biasanya berupa motivasi belajar atau bermain edukatif. Tema dalam Nuretta adalah "Let's Reach the Star". Tema ini diambil dengan pertimbangan bahwa kriteria naskah seharusnya berkaitan dengan kegiatan sehari-hari, memiliki nilai moral, etika social, dan motivasi. Hal ini berarti bahwa jika kita ingin menjadi orang luar biasa, kita harus memiliki banyak kontribusi kepada orang lain, dan berkepribadian baik. Kecerdasan bukanlah segalanya, tetapi dengan etika dan karakterlah yang akan membuat orang menjadi segalanya. Tidaklah cukup untuk menjadi pintar, karena orang yang sukses tidak hanya pintar tetapi juga baik untuk orang lain. Itulah pencapaian luar biasa yang sebenarnya yang dimaksud oleh tema ini.

b.Mengoleksi nursery rhymes 
Pengoleksian ini berupa segi liriknya dan cara melagukannya. Pengumpulannya didapat dari banyak referensi antara lain buku diktat sastra 
Inggris, majalah, artikel dan Video Compact Disc. Diantaranya adalah Baa Baa Black Sheep, Hickory Dickory Dock, Are You Sleeping, Old Mac Donald, Humpty Dumpty, dan lain-lain. Berikut adalah judul nursery rhymes yang masih eksis (buku nursery rymes).

Tabel 1: Kumpulan Judul Nursery Rhymes

\begin{tabular}{|l|l|}
\hline Baa, Baa, Black Sheep & Humpty Dumpty \\
\hline Hickory, Dickory, Dock & One, Two \\
\hline Jack and Jill & Are You Sleeping \\
\hline Two Little Hands To Clap, Clap, Clap & Twinkle, Twinkle Little Star \\
\hline London Bridge Is Falling Down & Old Mac Donald \\
\hline Marry Had Little Lamb & Erie Canal \\
\hline The Happy Wanderer & Silent Night \\
\hline The Mulberry Bush & Over In the Meadow \\
\hline Old Black Joe & Lazy Mary (Will You Get Up) \\
\hline The Gingerbread Man & Michael, Row the Boat Ashore \\
\hline Red River Valley & My Bonnie Lies Over the Ocean \\
\hline In And Out the Dusky Blue Bells & Swing Low, Sweet Chariot \\
\hline This Old Man & I've Been Working in the Railroad \\
\hline My Old Kentucky Home & Ding Dong Bell \\
\hline A Baby & Hop a Little \\
\hline Pussy-Cat, Pussy-Cat & Teddy Bear, Teddy Bear \\
\hline Bits of Paper & Yankee Doodle \\
\hline Polly Wolly Doodle & The Wheel on The Bus \\
\hline
\end{tabular}

c. Menyeleksi nursery rhymes

Proses penyeleksian ini harus yang berhubungan dengan tema. Misalkan temanya adalah motivasi belajar, contoh nursery rhymes-nya adalah TwinkleTwinkle Little Star dan London Bridge. Sehingga tidak semua koleksi nursery rhymes digunakan dalam membuat naskah tersebut. Dengan mendengarkan semua koleksi dan mempertimbangkan aspek-aspek tersebut, maka diputuskan untuk menggunakan nursery rhymes berikut ini sebagai alur naskah yaitu Twinkle-Twinkle Little Star, Are You Sleeping ?, Baa, Baa Black Sheep, dan 
London Bridge is Falling Down.

d.Menganalis, Menafsirkan, dan menemukan nilai moral dalam nursery rhymes
Simpson
(1997:

menyatakan bahwa dalam menafsirkan makna karya sastra, tidak cukup mengetahui makna harfiahnya saja, tetapi juga makna dibalik kata itu sendiri. Oleh karena itu, dalam langkah keempat ini, menganalisis dan menafsirkan nilai-nilai moral dan unsur budaya yang terkandung dalam nursery rhymes merupakan hal penting untuk dilakukan.

$\begin{array}{rccc}\text { Twinkle- } & \text { Twinkle Little Star } \\ \text { menggambarkan } & \text { tentang } & \text { situasi dan }\end{array}$
kondisi yang indah dimana puncak impian itu terjadi dan menjadi nyata. Lirik "How I wonder what you are?" yang berarti bahwa sebenarnya, kita tidak tahu apa impian/cita-cita itu. Yang kita tahu adalah bahwa impian/cita-cita itu sangat penting dalam kehidupan kita, tetapi kebanyakan dari kita tidak mengerti. "Up above the world so high" menggambarkan bahwa kita harus memiliki impian/cita-cita besar untuk membuat hidup kita penuh warna dan memiliki semangat besar dalam mencapai kebahagiaan kita. "like a diamond in the sky": jika kita memiliki impian/cita-cita yang bagus dan kita melakukan yang terbaik untuk mengejar mimpi itu, pasti hidup kita akan penuh warna. Jangan lupa belajar dengan giat untuk meraih kesuksesan demi masa depan yang cerah.

Bait "are you sleeping, are you sleeping, brother John" dapat diartikan bahwa ada seseorang yang masih tidur di tempat tidur. "morning bells are ringing. Ding dong ding", berarti bahwa seseorang masih tidur dan alarm berdering dan matahari mulai terbit di timur. Dengan demikian, seseorang di sini adalah anak yang malas. Dia selalu telat bangun tidur dan dibangunkan oleh saudaranya. Nilai moral yang dapat diambil adalah kita harus rajin dan disiplin sebagai anak lakilaki. Kita seyogyanya bangun pagi-pagi sebelum matahari terbit. Seorang anak yang pintar dan cerdas selalu bangun pagipagi.

Baa Baa Black Sheep menyiratkan bahwa dalam kondisi apapun, kita harus bersyukur kepada Tuhan YME atas segala nikmat-Nya. Sebagai rasa terima kasih, kita harus menjadi manusia yang murah hati, suka memberi dan membantu, berbagi dengan apa yang kita miliki kepada orang lain agar sama- sama merasakan kebahagiaan.

"London Bridge is Falling Down" dapat diinterpretasikan bahwa kita tidak boleh menjadi orang yang mudah yang putus asa. Kata "falling down" yang berarti runtuh, jatuh, hancur menggambarkan kondisi yang rapuh akan gempuran realita. Oleh karena itu, harus punya semangat bangkit untuk mengatasi masalah.

e. Mengaplikasikan nilai moral tersebut dalam sebuah dialog/ percakapan 
Berikut adalah cuplikan naskah Nuretta:

Miss Taffy : No, dear. A successful person is not only smart but also good to others. Do you know how to be good to others?.

Rose: Me....!

Baa, baa black sheep Have you any wool? Yes sir, yes sir

Three bags full One for my master

One for his dame

And one for the little boy That lives down the lane.

Miss Taffy : What do you mean, Rose?

Rose : We have to be a generous man, giving something to each other, sharing what we have, our happiness with the others.

Miss Taffy : Well done Rose, thank you very much.

Rose : Thank you Miss Taffy.

f. Menyusun naskah secara runtut (plotting)

Adapun latar belakang / setting dari naskah ini adalah rumah (keluarga) dengan digambarkan oleh lirik Are You Sleeping, Are You Sleeping, Brother John ? dan London Bridge is Falling Down. Yang kedua adalah di ruang kelas (sekolah) dengan diilustrasikan oleh lirik Twinkle- Twinkle Little Star dan Baa, Baa Black Sheep.

g. Memberikan judul pada naskah

Judul biasanya merupakan kata atau frasa yang mampu menggambarkan isi dari Nuretta yang aka dipelajari bersama. Adapun judul naskah Nuretta tersebut adalah "Your Dream, Make it Happen”. Raihlah mimpi/cita-cita setinggi mungkin. Dalam menggapainya kita tidak boleh kalah dan menyerah kepada keadaan, jangan bersedih, terus berjuang, bantu sesama yang membutuhkan, dan selalu semangat. Jatuh, bangkit lagi. Jatuh lagi, bangkit lagi. Dan begitu selanjutnya sampai ajal menjemput.

Selanjutnya adalah latihan (rehearsal). Latihan- latihan dilakukan guna memberikan informasi dan arahan model pembelajaran ini bagi siswa. Selama dalam latihan para siswa diwajibkan mengisi Skill Development Form (form perkembangan kemampuan) sebagai tolok ukur peningkatan kemampuan bahasa siswa melalui strategi ini. Para pelatih juga mengisi hal yang sama sebagai evaluasi dalam setiap pertemuan. Tim memberikan tiga keterampilan pelatihan kepada anakanak seperti belajar bahasa Inggris melalui operet. Mereka membaca, mendengarkan, dan berbicara. Tim juga melatih mereka komponen bahasa seperti menguasai kosa kata, pengucapan, intonasi, gerakan dan ekspresi serta budaya karena keterampilan dan komponen bahasa itu 
saling terkait satu sama lain dan berguna dalam memerankan tokoh baik dalam opera, drama, maupun film. Agar belajar lebih efektif dan efisien, tim membuat jadwal termasuk aktivitas yang dilakukan serta informasi tentang apa yang dipelajari dalam setiap pertemuan.

Tahap kedua adalah pelaksanaan. Dalam melaksanakan model pembelajaran Nuretta, seyogyanya semua yang terlibat merasa benar- benar bebas. Hal ini dapat memberikan stimulus pada anak untuk meresapi peran baik oleh dirinya maupun dari teman lainnya. Pelaksanaanya boleh dimana saja, dan kapan saja, asalkan semua bisa berpartisipasi dengan baik. Jika akan diterapkan dalam class room, maka siswa yang lain dapat menonton serta mengevaluasi penampilan teman mereka didepan kelas. Tidak menutup kemungkinan bila diadakan suatu pertunjukan yang lebih besar lagi seperti pementasan di atas panggung, atau dijadikan sebuah film dokumenter tentang kreativitas siswa.

Tahap terakhir adalah penilaian. Penilaian adalah langkah terakhir yang harus dilakukan pada akhir pelaksanaan implemetasi Nuretta Deviana. Ada dua hal yang yang menjadi titik fokus penilaian, yaitu keterampilan berbicara dan karakter melalui rubrik yang sudah disiapkan. Dalam hal ini, tim menggunakan penilaian otentik untuk mengetahui hasil peningkatan berbicara. Guru maupun komentator dapat memberikan sebuah penilaian dengan menggunakan authentic assessment (penilaian autentik). Penilaian autentik adalah dimana siswa dapat menerapakn informasi dan keterampilan akademik baru dalam situasi nyata untuk tujuan tertentu.

Johnson

(2003:296)

mengemukakan ada 4 (empat) jenis penilaian autentik, yaitu: portofolio, pengukuran kinerja, proyek, dan jawaban tertulis secare lengkap. Penilaian autentik pada Nuretta Deviana ini menggunakan pertunjukan sebagai alat penilaian, seperti hanya pembuatan proyek dan portofolio.

\subsection{Keterampilan dan komponen bahasa Inggris yang dilatih melalui Nuretta \\ Deviana}

a. Language Skills (Keterampilan Bahasa) Adapun keterampilan bahasa yang dilatih melalui model pembelajaran bahasa Inggris menggunakan Nuretta Deviana adalah speaking (paling utama), listening, dan reading. Banyak cara yang dapat digunakan dalam meningkatkan keterampilan berbicara. Lazaraton (2001: 106) mengemukakan bahwa ada empat cara yang dapat diimplementasikan 
untuk mengasah kemampuan berbicara, yaitu: diskusi (discussion), berpidato (speech), bermain seni peran (role plays), dan percakapan (conversation). Role Plays sangat cocok untuk mengajarkan pada anak tentang variasi sosio-budaya dalam tindakan berbicara (speech act). Mereka akan belajar bagaimana bertindak sesuai dengan situasi dan kondisi masa kini; mengeluh, kesuakaan, ataupun kecewa. Dalam model ini, selain melakukan permainan peran, anak-anak secara tidak sadar juga melakukan percakapan di antara para aktor. Oleh karena itu, para siswa mengetahui bentuk kalimat dan artinya dalam berbahasa Inggris.

Selain speaking, keterampilan mendengar (listening) akan secara otomatis terlatih. Dalam pembelajaran bahasa Inggris melalui Nuretta Deviana keterampilan listening terasah dengan mendengarkan dan menjawab pertanyaan secar komprehensif dari lawan bicara. Dengan menggunakan model ini pula, siswa belajar mendengarkan, mengulang, dan merespons. Mereka mengulangi apa yang tim peneliti katakan, dan menjawab apa pertanyaan tersebut. Ketika mereka menjawab, sebenarnya mereka belajar tentang mendengarkan secara responsif. Mendengarkan secara responsif adalah mendengarkan dalam rentang waktu yang relatif singkat (ucapan, pertanyaan, perintah, pemeriksaan pemahaman, dll) untuk memberikan tanggapan dengan singkat pula (Brown, 2004: 120). Selain itu, dengan adanya interactive listening (mendengarkan interaktif) akan meningkatkan keterampilam mendengar, berfikir secara kritis, dan kemampuan berbicara efektif.

Keterampilan yang terkahir adalah reading. Dalam Nuretta Deviana, siswa dapat mempelajari bagaimana cara membaca teks dengan baik dan benar sesuai cara baca (pronunciation) dan penekanan (stressing). Selain itu, Nuretta mengajarkan mereka cara menyanyikan nursery rhymes, membuat mereka memahami teks itu sendiri dan menghubungkannya dengan kegiatan sehari-hari mereka, dan untuk memperkenalkan bahwa belajar bahasa Inggris adalah mudah dan menyenangkan.

b. Language Components (Komponen Bahasa)

Adapun komponen bahasa yang dapat dipelajari melalui Nuretta adalah vocabulary (kosakata). Secara tidak langsung, perbendaharaan kata siswa semakin bertambah. Perubahan kelas kata (part of speech) adalah yang utama baik noun (kata benda, verb (kata kerja), adjective (kata sifat), maupun adverb (kata keterangan). Siswa semakin mudah 
dalam menghafal kosa kata tersebut, karena selain dihafal, mereka juga sering menemuinya sehari- hari.

\begin{abstract}
Selain kosakata, Aspek yang terpenting adalah anak dapat meningkatkan mutu pelafalan mereka dalam kata bahasa Inggris. Kemampuan ini sangat jarang sekali diperhatikan oleh para guru di sekolah. Padahal, konsonan dan vowel dalam bahasa inggris ada yang tidak ada dalam bahasa Indonesia.
\end{abstract} Contohnya adalah long $/ \eta /$, think / $\theta /$, that / d/, shop / /, Jacky /db /, decision / $3 /$, choose / $t$ /. Selain itu anak juga mempelajari stressing (penekanan kata). Pelafalan kata maupun kalimat terasah semaksimal mungkin sejalan dengan latihan yang telah diberikan. Dengan memberikan pelatihan pelafalan berulang-ulang akan membuat pelafalan terasa mirip seperti bunyi aslinya (native speaker).

Komponen selanjutnya adalah gesture and expressions. Sitorus (2003: 81) menjelaskan bahwa aktivitas expresi adalah bagian dari pikiran dan perasaan kita. Impuls, perasaan, atau reaksi yang kita miliki menimbulkan energi dalam diri yang selanjutnya mengalir keluar, mencapai dunia luar dalam bentuk yang bermacam- macam, salah satunya adalah gestur. Dalam Nuretta Deviana ini, anak belajar mengenai ekspresi dan mengaplikasikannya dengan gestur dalam seni peran. Contoh: ekspresi meminta pertolongan orang lain. Could you tell me about it?. Gestur yang digunakan adalah dengan sikap berharap dan membutuhkan.

Komponen bahasa yang terakhir adalah Language Culture. Bahasa mempunyai budaya sendiri. Dengan budaya suatu bahasa siswa menjadi lebih mengerti bagaimana bahasa itu digunakan secara tepat, baik dan benar. Good night bukanlah ucapan selamat malam ketika bertemu pada malam hari, melainkan ucapan ketika akan tidur atau berpisah pada malam hari. Terkadang dalam role play/ drama menggunakan kombinasi dua budaya bahasa, misalnya budaya Indonesia dengan Inggris. Hal inilah yang sering kita sebut dengan istilah "Cross- Cultural Content". Dalam Nuretta, siswa belajar kombinasi dua budaya tersebut.

Adapun budaya Indonesia yang pertama adalah Percaya pada Yang Maha Esa. Ini tercermin ketika siswa mengucapkan doa sebelum memulai pelajaran. Artinya sebagai warga negara Indonesia, mereka harus memiliki agama sebagai cara dan pandangan hidup. Kedua adalah tidak bersifat individualisme. Budaya individualistis lebih mementingkan diri sendiri dan 
lebih menekankan pada tujuan individu. Sebagai orang Indonesia, kita harus peduli kepada orang lain dan siapa pun mereka karena kita manusia social yang saling membutuhkan. Nilai ini dapat dilihat dalam naskah scene Baa, baa black sheep. Ketiga adalah budaya kolektivitas dalam memecahkan masalah. Hal ini berarti musyawarah dalam setiap mengambil jalan keluar dari suatu masalah. Terlebih masalah keluarga yang terjadi dlam kehidupan sehari-hari. Hal ini tercermin dalam scene are you sleeping, are you sleeping, brother John?.

Mempelajari budaya adalah bagian penting dari belajar bahasa Inggris pula karena budaya mengajarkan bagaimana bahasa Inggris sebenarnya diterapkan dalam kehidupan nyata dengan tepat. Dalam Nuretta, selain budaya Indonesia itu, budaya Inggris yang dapat ditemukan antara lain: (1) greeting and addressing. Hal ini dapat dilihat dari penggunaan Mr., Mrs., dan Miss. (2) nursery rhymes itu sendiri adalah sebagai hasil kebudayaan Inggris. Banyak fitur budaya yang ditemukan di dalamnya dan diturunkan secara turuntemurun melalui tradisi lisan dari satu generasi ke generasi berikutnya (baik dari orang tua ke anak atau dari anak yang lebih besar ke anak yang lebih kecil). Di sisi lain, Indonesia juga nursery tersendiri yang sering disebut dengan "Lagu dolanan Anak" seperti “Lir Ilir”, “Jaranan”, dan sebagainya.

\subsection{Pembentukan karakter siswa melalui implementasi Nuretta Deviana}

\begin{abstract}
Pembentukan karakter siswa dapat dibentuk melalui banyak jalan dan cara. Salah satunya adalah melalui seni pertunjukan (dalam hal ini adalah Nuretta). Seni pertunjukan diyakini dapat membantu proses pembelajaran karakter siswa, karena dalam karya sastra terkandung nilai-nilai positif dan nilai budaya, sosial, moral, kemanusiaan, hingga keagamaan. Seni pertunjukan sebagai media untuk melukiskan kejadian-kejadian yang berisikan nilai-nilai karakter akan menjadikan siswa lebih mudah untuk memahami dan menyerap nilai- nilai karakter tersebut. Hal ini disebabkan karena siswa belajar secara audio visual serta aplikasi langsung (dalam sebuah pementasan). Anak-anak memiliki pandangan yang relatif mendalam tentang karakter/ watak manusia serta hidup dan kehidupannya. Melalui seni pertunjukan, siswa mendapatkan pemahaman tentang psikologi karakter manusia sehingga siswa akan mendapatkan pengetahuan yang lebih mendasar tentang sifat-sifat manusia
\end{abstract}


lain (pada umumnya) dan tentang dirinya sendiri.

Nuretta mampu memberikan kesempatan kepada siswa untuk mempelajari psikologi manusia dengan berbagai perilakunya dengan peran/tokoh yang diperankannya. Tentunya, peran tokoh itu akan dihayatinya dengan baik, sehingga tanpa sadar prosesi itu akan sangat membantu siswa dalam proses pendewasaan diri. Siswa mengidentifikasikan diri mereka dengan tokoh- tokoh yang dibawakannya dan mengetahui dengan baik masalah-masalah tokoh tersebut. Demikian pula, siswa tahu secara persis nilai-nilai moral yang diperjuangkan oleh tokoh-tokoh, sehingga siswa menjadi cukup terlatih dalam upaya memecahkan masalahnya sendiri dalam kehidupan sehari-hari seperti malas belajar, tidak disiplin, intoleran, dan lain sebagainya.

Melalui Nuretta siswa menjadi terbiasa, lebih mudah dan lancar untuk mengemukakan pikiran dan perasaan secara logis dan sistematis di depan orang banyak secara lisan. Di samping itu, siswa memperoleh kekayaan kosakata yang luar biasa yang mungkin tidak akan mereka dapatkan dalam bahasa yang sedang mereka pelajari di sekolah. Di sekolah mereka belajar secara tekstual, tetapi di sini mereka akan belajar secara tekstual dan kontekstual.

Seperti yang telah diketahui bersama, seni pertunjukan adalah kegiatan kolektif yang memerlukan kesetiaan, kedisiplinan yang tinggi, rasa tanggung jawab, dan kerjasama yang baik. Begitu juga dalam implementasi Nuretta Deviana. Maka, tidak mustahil pada diri siswa akan tertanam dalamdalam sikap atau perilaku disiplin, kerja keras, gotong-royong dan bekerjasama dalam rangka menggapai tujuan bersama. Tentunya hal ini tidak lepas dari seorang pengarah/pelatih/guru/pengajar yang mempunyai peranan penting untuk memberikan pengarahan dalam setiap tahapan nuretta. Sebagaimana yang dikemukakan oleh Vygotsky bahwa siswa sebaiknya belajar melalui interaksi dengan orang dewasa dan teman sebaya yang lebih mampu. Interaksi sosial ini memacu terbentuknya ide baru dan memperkaya perkembangan intelektual siswa (Yohanes: 2010).

Satu hal yang harus disadari bersama bahwa bermain merupakan dunia masa kanak-kanak. Bermain bagi anak merupakan proses mempersiapkan 
diri untuk masuk ke dalam dunia orang dewasa, cara bagi anak untuk memperoleh serpihan pengetahuan tentang berbagai hal, menumbuhkan hasrat bereksplorasi, melatih pertumbuhan fisik dan imajinasi, berlatih berinteraksi dengan orang dewasa dan anak lain, dan berlatih menggunakan kata-kata (Amini: 2014). Oleh karena itu, Nuretta juga mengedepankan aspek psikologis siswa dengan ciri khas masanya. Learning by doing adalah strategi implementasi dari Nuretta Deviana.

\subsection{Hambatan dan solusi yang muncul selama proses}

\section{pembelajaran Nuretta Deviana}

Ada dua faktor hambatan yang muncul dalam pelaksanaan pembelajaran bahasa Inggris dengan model Nuretta Deviana yaitu faktor internal dan eksternal. Faktor internal tersebut adalah :

a. Siswa memiliki tingkat kepercayaan diri yang rendah dalam mengucapkan kata- kata bahasa Inggris. Itu bisa dilihat ketika mereka melakukan latihan dengan suara lemah (seperti takut salah).

b. Siswa merasa kesulitan untuk mengucapkan beberapa suara terutama dalam menghasilkan suara seperti think $/ \theta /$, that $/ \partial /$, sheep $/ \int /$, John / ds /, teacher / $t$ I/.

c. Kemampuan siswa dalam berakting/berekspresi berbeda satu sama lain.

Adapun solusi yang tim berikan guna meminimalisir hambatan-hambatan tersebut adalah sebagai berikut :

a. Melakukan olah vokal dan memberikan semangat dalam mempelajari Bahasa Inggris. "salah tidak mengapa. Lebih baik salah hari ini, dari pada salah di masa depan”. Kuncinya dalam melatih siswa SD adalah sabar dan kontinyu.

b. Masalah pelafalan beberapa kata di atas adalah dengan cara membandingkannya dengan pelafalan bahasa Arab. Dipilih bahasa Arab karena bahasa asing lain yang lebih akrab bagi mereka adalah bahasa Arab. Sebagai contoh: / $\theta /$ think mirip dengan / $\Xi$ / tsalaatsah, / $\partial$ / yang mirip dengan / ش / d dzaalika, / / / domba mirip dengan / / syamsyun, dan / ds / jacky mirip dengan / ج / janubun. Sayangnya, It / tidak memiliki perbandingan dalam bahasa Indonesia dan bahasa Arab. Karena itu, tim hanya dilatih untuk / $t$ / secara teratur dan terus menerus.

c. Kemampuan siswa dalam berakting/ berekspresi yang bervariasi antar individu dapat diatasi dengan menokohkannya sebagai karakter pendukung. Dengan ikut berpartisipasi, setidaknya mereka dapat menghafal nursery rhymes dan 
menemukan implementasi nilai moralnya dalam tindakan temanteman mereka.

Adapun faktor eksternal yang menghambat adalah berkaitan dengan alokasi waktu untuk latihan karena para guru tampaknya berkonsentrasi pada materi lain untuk menghadapi ujian akhir semester maupun ujian kenaikan kelas. Dengan kata lain, masih ada keterbatasan waktu dalam mengimplementasikan Nuretta di Sekolah Dasar. Setidaknya, hambatan tersebut dapat diatasi dengan menjadikan pembelajaran Nuretta inisebagai aktivitas ekstrakurikuler yang mendukung intra-kurikuler.

\section{SIMPULAN}

Berdasarkan hasil pembahasan di atas, dapat disimpulkan bahwa 1) Nuretta Deviana dilakukan dengan mengadakan persiapan, pertunjukan, dan penilaian. Persiapan meliputi pembuatan naskah operetta dan latihan. Pertunjukan dapat dilakukan kapanpun dan dimanapun. Penilaian dapat menggunakan authentic assessment yang berupa pertunjukan atau pementasan (performance), 2) Nuretta Deviana dapat mengasah keterampilan dan komponen bahasa inggris anak. Keterampilan tersebut antara lain speaking, listening, reading serta komponen bahasa yang meliputi vocabulary, Grammatical Structures, Pronunciation, Gesture and expressions, Language Culture, 3), pembentukan karakter dibentuk dengan menanamkan nilai-nilai luhur budaya yang diakulturasikan dengan budaya Inggris yang tidak berseberangan malalui naskah Nuretta. 4) Kendala waktu untuk mengadakan Nuretta Deviana ini dapat diatasi dengan menjadikan strategi ini sebagai kegiatan ektrakurikuler. Kemampuan akting anak dapat dapat diatasi dengan intensitas latihan yang diberikan secare bertahap.

\section{DAFTAR PUTAKA}

1) Amini, Mukti. (2014). Perkembangan dan Konsep Dasar Pengembangan Anak Usia Dini. repository.ut.ac.id

2) Ismawati, E., Santosa, G. B., \& Ghofir, A. (2016). Pengembangan Model Pembelajaran Sastra Indonesia Berbasis Pendidikan Karakter Di Sma-Smk Kabupaten Klaten. (pp. 588-596). Yogyakarta: Universitas Ahmad Dahlan Yogyakarta.

3) Johnson , E. (2002). Contextual Teaching and Learning: what it is and why it's here to stay. California: Corwin Press.

4) Kang Shin, J. (2006). Ten Helpful Ideas for Teaching English to Young Learners.

5) English Teaching Forum, 2-3.

6) Mustika, N. (2018). Penggunaan Strategy Role Play Untuk Meningkatkan Skill Dan Ketertarikan Siswa Dalam Speaking. Prosiding Seminar Kesehatan Perintis.

7) Puspasari, A., Utami, F. K., Widhayanti, A., \& Kaltsum, H. U. (2018). 
Implementasi Pembelajaran Bahasa Inggris Kelas SME Berbasis Multiple Intelligences Di MIM PK

8) Kartasura. The 8th University Research Colloquium , 422-429.

9) Qorri'aina, F. D., Haryanto, S., \& Anitah, S. (2017). Model Pembelajaran Terpadu Modifikasi Wolfinger di Sekolah Dasar. Prosiding Seminar Pendidikan Nasional, (pp. 7179). Surakarta.

10) Ratminingsih, N. M., \& Budasi, i. G. (2017). Pembelajaran Bahasa Inggris Berbasis Tema Melalui Lagu Kreasi Di Sekolah Dasar. 31-45.

11) Susanty, D. (2017). Model Pembelajaran Role Playing Pada Mata Pelajaran Bahasa Indonesia. Prosiding Seminar Nasional Tahunan Fakultas Ilmu Sosial Universitas Negeri Medan, (pp. 259-261). Medan.

12) Sustiawati, L. N., Suryatini, N. K., \& Mayun Artati, A. A. (2018). Pengembangan Desain Pembelajaran Seni Tari Di Sekolah Dasar Berbasis Localgenius Knowledge Berpendekatan Integrated Learning. MUDRA Jurnal Seni Budaya, 128143.

13) Yektiningtyas, W., \& Rahayu, B. (2017). PEMBELAJARAN BAHASA INGGRIS UNTUK SEKOLAH DASAR MELALUI CERITA RAKYAT ANAK PAPUA. Jurnal Pengabdian Papua, 53-58.

14) Yohanes, Rudi Santoso. (2010). TEORI VYGOTSKY DAN IMPLIKASINYA TERHADAP PEMBELAJARAN MATEMATIKA. Widya Warta No. 02 Tahun XXXIV / Juli 2010.

15) Zalta, G. (2006). Using Drama with Children. English Teaching Forum, 24-27. 